\title{
NOTAS SOBRE LA JURISDICCIÓN ÉTICA DE LOS COLEGIOS PROFESIONALES
}

\author{
Pablo Fuenzalida Cifuentes*
}

"Ellos tratan constantemente de escapar de las tinieblas de fuera y de dentro a fuerza de soñar sistemas tan perfectos que nadie necesitará ser bueno.

Pero el hombre que es seguirá como una sombra al hombre que finge ser"

T.S. Eliot, Los Coros de la Piedra

\begin{abstract}
RESUMEN
En estas notas se exploran las posibles consecuencias normativas de la reforma constitucional relativa a los colegios profesionales. Para ello, se comparará la situación de dichas instituciones antes de la reforma. Posteriormente se analizarán las posibles consecuencias de la reforma de 2005. Finalmente, se discutirá si los colegios profesionales realmente ganaron o perdieron a la luz de su propia autonomía.
\end{abstract}

\section{COLEGIOS PROFESIONALES - REFORMA CONSTITUCIONAL - JURISDICCIÓN}

\section{Notes on ethical jurisdiction of professional associations}

\begin{abstract}
In this notes some possible normative consecuences of the constitutional amendment about de professional bar associations are explored. To accomplish thar objective, it will be compared the situation of those institutions before the amendment. Later, this paper analyzes the possible consecuences of 2005's amendment. Finally, it discusses if professional bar associations, from the look of their own autonomy, have really won or lose about it.
\end{abstract}

\section{PROFESSIONAL BAR ASSOCIATIONS - CONSTITUTIONAL AMENDMENT - JURISDICTION}

* Licenciado en Ciencias Jurídicas y Sociales, Ayudante ad-honorem, Departamento de Ciencias del Derecho, Facultad de Derecho, Universidad de Chile, pabloafc@gmail.com. Deseo agradecer al profesor Lucas Sierra y a Mario Valderrama por sus comentarios a una versión previa de este artículo. Los errores son sólo míos. Trabajo recibido el 16 de agosto de 2007 y aceptado para su publicación por el Comité Editorial el 22 de octubre de 2007. 


\section{INTRODUCCIÓN}

$\mathrm{E}$ n estas notas intento esbozar los posibles alcances que la última reforma constitucional en materia de jurisdicción de los colegios profesionales produciría para nuestro ordenamiento jurídico. En comparación al resto de las reformas constitucionales del año 2005, la que aquí se comenta pasó casi desapercibida, probablemente porque la misma no implicaría el fin de la transición ni la eliminación de un enclave autoritario, como se señaló respecto al conjunto de ellas. La Ley 20.050 agregó al inciso cuarto del artículo 19 número 16, que versa sobre la libertad de trabajo, un nuevo párrafo facultando a los colegios profesionales para conocer de las reclamaciones que se interpongan ante ellos relativas a la conducta ética de sus miembros. Y por otra parte, señala que los profesionales no asociados a dichas instituciones deberán ser juzgados sobre dicha materia por los tribunales especiales que se creen para dicho efecto.

Esta reforma constitucional se produce dentro del contexto establecido por el Decreto Ley 3.621 (DL), "fija normas sobre Colegios Profesionales", publicado el 07 de febrero de 1981, el cual ha sido considerado la versión nacional de la ley francesa L' Chapelier. Dictada el año 1791, en plena revolución, eliminó todo tipo de corporaciones de la misma clase y profesión, prohibiendo su restablecimiento bajo cualquier pretexto o forma, e incluso teniendo por sedicioso a cualquiera de esos grupos si ellos atentaban contra el libre ejercicio de la industria y del trabajo. En el caso chileno, el DL 3.621 suprimió, entre otras modificaciones relevantes, la colegiatura obligatoria de una misma clase de profesionales así como el control disciplinario que los colegios profesionales ejercían sobre sus miembros. A su vez, la Constitución vigente consagra como derechos fundamentales las libertades de asociación y de trabajo en un lenguaje que claramente recibe el eco producido anteriormente por dicha legislación.

La reforma del año 2005 podría ser vista como un triunfo gremial, marcado por la historia previa al DL 3.621 y a la Constitución de 1980. También podría leerse como un regreso de ideas corporativistas, como lo fueron alguna vez los senadores designados y vitalicios. Ambas afirmaciones se sustentan en el desarrollo jurídico que los colegios profesionales han tenido en nuestro país, materia sobre la que versa el primer apartado. Por otra parte, cabe dilucidar cuál es el alcance normativo concreto de la reforma, especialmente si ella implica recuperar aquella situación previa al DL 3.621, lo que será tratado en el segundo apartado. Por último, a mi parecer los colegios profesionales no deberían ser tan optimistas con la reforma constitucional, la que podría encubrir una suerte de regalo troyano respecto a la autonomía de estas instituciones, como se verá en el último apartado.

\section{SÍNTESIS HISTÓRICA}

Sin entrar en los detalles históricos sobre el origen de los colegios profesionales, que para algunos autores podría remontarse a la antigua Roma, en su pasado más reciente, bajo la vigencia de la Constitución de 1925, los colegios profesionales fueron concebidos 
como personas jurídicas de derecho público, y más aún, como corporaciones públicas paraestatales que perseguían un fin de interés general. ${ }^{1}$ Dicha concepción sobre su naturaleza jurídica se produjo bajo el Estado de Compromiso, momento histórico en el cual se fue desarrollando "la concepción de que el Estado debe tener una actitud protectora para todos los estratos de la sociedad, en la medida en que estén involucrados en el trabajo material o administrativo, es necesario ir creando nuevos organismos estatales o paraestatales y con ello incrementar cuantitativamente la administración pública. Es un dilema sin salida, ya que tampoco podía prescindirse de la idea, tradicional y nueva a la vez, de que el Estado es el agente del bien común”. ${ }^{2}$ Los colegios profesionales pasarían a ser una esfera dentro del Estado, lo cual explicaría que se les otorgaran privilegios y derechos respaldados por disposiciones legales, e incluso, que el mismo Estado les delegara determinadas responsabilidades de decisión y control así como la inclusión de una partida específica dentro del presupuesto fiscal. ${ }^{3}$ Una de las principales potestades reconocidas a los colegios profesionales sería el control disciplinario sobre sus asociados, los cuales, según las leyes relativas a cada entidad, estaban obligados a afiliarse o asociarse a ellos para poder ejercer su profesión respectiva.

Para ilustrar lo anterior basta echar una mirada sobre las leyes de algunos de los colegios profesionales. El más antiguo de ellos, el Colegio de Abogados, fue creado por el DL 406 de 1925. El Colegio de Abogados se encontraba dividido en Consejos, uno General y los demás Provinciales. A estos les correspondía resolver en calidad de amigable componedor las cuestiones que se suscitaran entre abogados, y como árbitro en materia de honorarios entre el abogado y su cliente. El título de abogado se otorgaba por una comisión que entre sus integrantes contemplaba al Presidente del Consejo General de Abogados de Santiago. El DL establecía como requisito para poder ejercer la profesión que el abogado se inscribiera en un registro especial en el distrito jurisdiccional de su residencia, y sólo quienes se encontraban inscritos podrían ejercer ante todos los tribunales del país. ${ }^{4}$ Posteriormente dicho DL fue derogado por la Ley 4.409 de 1928. En

${ }^{1}$ Así lo señala Silva C., E., Derecho Administrativo chileno y comparado, Santiago, Editorial Jurídica de Chile, 1961, tomo II, pp. 333-338. Cabe señalar que las leyes respectivas no califican la personalidad jurídica de los colegios que ellas crean en público o privado.

${ }^{2}$ Góngora, M., Ensayo histórico sobre la noción de Estado en Chile en los siglos XIX y XX, Santiago, Editorial Universitaria, 1998, p. 221. Mirado el período a nivel de los discursos, se podría señalar que en ellos se creía en el Estado, en su papel asistencialista y de su capacidad como proveedor de servicios. Al respecto Sierra, L., "Derecho, cambio social y los juristas en Chile: de la estridencia de los 60 al silencio de hoy", en AA.VV., El derecho como objeto de instrumento de transformación, Buenos Aires, Editores del Puerto, 2003, p. 42.

${ }^{3}$ Gyarmati, G., Las profesiones. Dilemas del conocimiento y del poder, Santiago, Ediciones Universidad Católica de Chile, 1984 , p. 35, cita dictámenes de la Contraloría que coinciden con lo señalado, por cuanto no sólo reconocen su naturaleza de personas jurídicas de derecho público sino que también a la obligación de acatar y cumplir sus resoluciones, incluso por la autoridad militar. A su vez, cita la jurisprudencia temprana de la Comisión Resolutiva, consagrada por el Decreto Ley 211/1973, la que justificaba la facultad de los colegios profesionales para fijar los aranceles mínimos a los cuales debían ceñirse los profesionales asociados, por ser dicha facultad un poder público que con su ejercicio se actualizaba periódicamente.

${ }^{4}$ Artículos 2, 4, 9, 13, 14, y 15 del Decreto Ley 406, que dicta disposiciones referentes al ejercicio de la profesión de abogado, publicado 27/03/1925. 
ella se mantuvieron los aspectos recién mencionados, y se agregaron otros relevantes, tales como el deber de formar anualmente el presupuesto de la institución, el cual debía ser aprobado por el Presidente de la República; dictar un arancel de honorarios con un máximo para cada juicio o gestión, el que regiría a falta de estipulación expresa entre el abogado y su cliente; debía someter a la aprobación de la Contraloría General de la República el balance económico de la institución; y por último, en lo relativo al ejercicio de la profesión, el postulante debía rendir un examen ante la Comisión que otorgaba el título. 5 Posteriormente, en el año 1948, se crearían el Colegio Médico de Chile y el Colegio de Dentistas de Chile. La institucionalidad de ambos era similar a la del Colegio de Abogados, salvo algunas diferencias, como, por ejemplo, el Presidente de la República debía aprobar el arancel de honorarios profesionales que los colegios dictaren; los miembros de los Consejos Regionales eran elegidos aplicando expresamente para tales efectos la Ley Electoral, a través del voto proporcional con cifra repartidora; para garantizar la inscripción en el registro especial de los profesionales se prohibía a las municipalidades otorgar patentes para el ejercicio de la profesión de médico cirujano o de cirujano dentista a quienes no comprobaren su inscripción pertinente. ${ }^{6}$ Por último, en similares términos fue creado el Colegio de Enfermeras, cuya ley enfatizaba la obligación de formar parte de éste respecto de todas las personas que ejercían dicha profesión. ${ }^{7}$

Bajo este esquema podría sostenerse la existencia de aquella categoría dogmática conocida como relación de sujeción especial. ${ }^{8}$ Dichas relaciones de sujeción especial fueron establecidas en la monarquía constitucional alemana con la finalidad de excluir el principio de legalidad, los derechos subjetivos públicos y el control judicial, permitiendo, en consecuencia, una amplia discrecionalidad al monarca, no limitada por el derecho, acentuando la dependencia de los individuos con la Administración Pública en favor de una determinada finalidad. Ello sucedería en el caso de los funcionarios públicos, los soldados, los reclusos y los estudiantes. ${ }^{9}$ Aunque no resulta una categoría tranquila en la

\footnotetext{
${ }^{5}$ Artículos 12 letra e), n), 29, 34 de la Ley 4.409, que crea el Colegio de Abogados, publicada $12 / 09 / 1928$.

${ }^{6}$ Ver artículos 9 letra c), 15, y 25 de las Leyes 9.263, que crea el Colegio Médico de Chile, publicada 10/12/1948, y 9.271, que crea el Colegio de Dentistas de Chile, publicada 17/12/1948. Ambas leyes son iguales, salvo por las instituciones y personas a quienes están dirigidas.

${ }^{7}$ Artículo 2 de la Ley 11.161, Crea una institución con personalidad jurídica denominada Colegio de Enfermeras, que se regirá por las disposiciones que señala, publicada 05/03/1953.

${ }^{8}$ Sobre esta categoría puede consultarse Mayer, O., Derecho Administrativo alemán, Buenos Aires, Depalma, 2a. ed., 1982, Vol. 1; Gallego, A., "Las relaciones especiales de sujeción y el principio de la legalidad de la Administración”, en Revista de Administración Publica, N³4, 1961, pp. 11-51; García M., R., Las relaciones de especial sujeción en la Constitución española, Madrid, Editorial Tecnos, 1992; Lasagabaster, I., Las relaciones de sujeción especial, Madrid, Civitas, 1994. En Chile puede consultarse Cordero, L., "Los particulares como sujetos de derecho en el Derecho Administrativo. Bases para una sistematización”, en Revista de Derecho Público, Facultad de Derecho, Universidad de Chile, Vol. 64, 2002, pp. 213-236, y Aldunate, E., "La titularidad de los derechos fundamentales", en Estudios Constitucionales, No 1, 2003, pp. 187-201.

${ }^{9}$ Recientemente el Tribunal Constitucional ha recogido dicha categoría dogmática respecto a los miembros de las Fuerzas Armadas en los fallos relacionados con la tragedia del caso Antuco. Ver fallos Rol 468-2006 de 9 de noviembre de 2006 y Rol 559 de 07 de junio de 2007.
} 
doctrina, y en Chile es prácticamente desconocida, su utilización parece razonable por cuanto permite distinguir entre la sujeción general al ordenamiento jurídico que todas las personas que se encuentran en el territorio nacional deben respetar, y la de aquellos que se ven en una situación de sujeción más intensa por esa calidad específica que le otorga esa relación jurídica. Pero la relación de sujeción especial que aquí se trata no sólo se diferencia por su novedad en comparación a las anteriores, por cuanto su origen con tal carácter data del siglo XX, sino que además en ella no se produce dicha relación de sujeción especial con un órgano de la Administración, sino que con una agrupación de profesionales, que fue originalmente establecida en el ejercicio de su derecho de asociación, pero que el Estado intervino, incluso arrogándose su creación. Durante esa época es sabido que la afiliación al colegio profesional respectivo era requisito necesario para poder ejercer como profesional, y ello implicaba someterse a las reglas propias de cada orden, por lo general manifestadas en códigos deontológicos. Esta situación jurídica presentaba lo que Correa ha denominado como anomalía constitucional, consistiendo ella en la gestión privada de funciones públicas, aunque en este caso ella sería mayor por cuanto fue el Estado el que "publificó" una actividad que era privada, y que nunca fue un servicio público concesible. ${ }^{10}$

Dicho escenario cambiaría drásticamente, aunque con un breve paréntesis constitucional. Con la promulgación del Acta Constitucional No 3 de 1976, se habría consagrado la posibilidad de que la ley exigiera la colegiación obligatoria, la cual sólo podría imponerse para el ejercicio de una profesión universitaria. Dicha Acta reflejaba los planteamientos de la Comisión Ortúzar, los que habrían sido seguidos por el Consejo de Estado, pero no por la Junta Militar, la cual suprimiría el precepto que consagraba la posibilidad de obligar a los profesionales a colegiarse. Ello se vio reflejado posteriormente en la Constitución de 1980.

Conforme con la posición libertaria que parte de su narrativa supone, la Constitución de 1980 rehizo el marco normativo de las asociaciones de profesionales. De alguna forma, la actitud libertaria que sustentan las elites gobernantes hacia las profesiones organizadas se parecía a la estrategia seguida por los revolucionarios franceses durante la Gran Revolución, actitud que fue graficada por la Ley Chapelier de 1971. Buscando una sociedad "atomizada" que se requería para una apropiada función del

${ }^{10}$ Correa, R., "En defensa de una aplicación exclusivamente vertical de los derechos constitucionales", en VI Congreso Mundial de Derecho Constitucional, 13 de enero de 2004, Santiago, Chile, p. 2. Respecto a la técnica conocida como publicatio, ella ha estado tradicionalmente referida a que "toda actividad de servicio público requería una declaración del legislador previa que reservara al Estado la actividad económica. Dicha declaración se conoce en la literatura jurídica como 'publicatio'. Mediante ella, se traslada a la esfera pública la titularidad de una propiedad o su ejercicio o ambas cosas a la vez, y el Estado entrega a los privados su gestión, mediante una concesión. Lo anterior condujo a una identificación del servicio público y la publicatio". Carmona, C., "Comentario No 1. Fallo Norgener", en Revista de Derecho Público, Facultad de Derecho, Universidad de Chile, Volumen 62, 2000, p. 320. También puede verse con provecho Fernández, T-R., "Del servicio público a la liberalización desde 1950 hasta hoy", en Revista de Administración Pública, $\mathrm{N}^{\circ}$ 150, 1999, pp. 57-73. 
mercado, las asociaciones de profesionales -como entidades intermedias entre los individuos y el Estado- fueron privadas de su carácter obligatorio, de casi todas sus funciones autorregulatorias y de casi todas su prerrogativas ${ }^{11}$.

Antes de la entrada en vigencia de la Constitución fue dictado el Decreto Ley 3.621 (07/02/1981), el cual, además de lo mencionado en la introducción, otorgaría el carácter de asociaciones gremiales a todos los colegios profesionales. Con ello, los colegios pasaron a regirse por la normativa pertinente a ellas, la cual fue establecida unos años antes por el Decreto Ley 2.757 (04/07/1979). El Decreto Ley 3.621 terminaría con el requisito de encontrarse afiliado a un Colegio o inscribirse en sus registros para poder ejercer una profesión u oficio; derogaría todas las disposiciones legales que los facultaban para conocer y resolver conflictos entre profesionales, con sus clientes o sobre infracciones a la ética profesional, y acabaría con la facultad de fijar aranceles de honorarios para sus asociados. ${ }^{12}$ "En otras palabras, desde el punto de vista legal las organizaciones ocupacionales pasaron a ser algo similar a un club social, perdiendo su anterior carácter integrador y de exclusividad con relación a su ocupación. Esta regla 'privatizó' la iniciativa para crear y mantener organizaciones de carácter profesional. Resumiendo, los aspectos asociativos de las profesiones fueron dejados a la discreción de sus practicantes". ${ }^{13}$ Constitucionalmente ello se reflejaría en el artículo 19 numerales 15, que consagra el derecho de asociación sin permiso previo, y 16, que prohíbe que la ley o autoridad pública alguna puedan exigir la afiliación a una organización como requisito para trabajar.

Estos cambios constitucionales y legales no fueron bienvenidos por la doctrina ni por los propios colegios, reducidos entonces a asociaciones gremiales. Incluso fueron tildados ambos cuerpos normativos como agresiones de carácter constitucional y legal. ${ }^{14}$ El debate ha versado sobre la posibilidad de volver a la regulación anterior de los colegios profesionales como personas jurídicas de derecho público, cumpliendo ellos una función pública, y por lo tanto concebidos como órganos paraestatales, acentuado por diversos

${ }^{11}$ Sierra, L., Legal Ethics in Chile: Professional Dilemmas and Challenges under Conditions of Modernization, inédito, 1995, p. 41. Traducción propia.

12 Transcribo aquí los considerandos 2 y 4 del Decreto Ley 3.621: "2.- Que los Colegios Profesionales, cuya inscripción se impone con carácter de obligatoria para el ejercicio de la profesión respectiva, constituyen la única excepción a la norma anteriormente citada [la libertad de trabajo y de afiliación y desafiliación], lo que ha significado favorecer condiciones proclives a la mantención de sistemas monopólicos en amplios e importantes sectores del país; 4.- Que, por otra parte, las facultades jurisdiccionales tanto para dirimir conflictos entre los profesionales o entre éstos y sus clientes como para velar por el cumplimiento de la ética profesional, otorgadas a los Colegios, pueden ser idóneamente ejercidas por los Tribunales de Justicia, estableciendo con este fin procedimientos adecuados, lo que evitará el contrasentido que la misma entidad encargada de la defensa y desarrollo de los intereses profesionales de sus miembros, conozca y resuelva sobre las faltas a la ética profesional cometidas por éstos en el ejercicio de su profesión”.

${ }^{13}$ Sierra, L., Legal Ethics in Chile..., cit., p. 42.

${ }^{14}$ Ríos, L., "Las asociaciones, el derecho de asociación y los colegios profesionales”, en XXX Jornadas Chilenas de Derecho Público, Revista Universidad de Valparaíso, Facultad de Derecho, Universidad de Valparaíso, 1999, tomo I, pp. 141-158. 
proyectos de ley que han intentado infructuosamente de modificar esta situación. ${ }^{15}$ Por otra parte, pese a la derogación expresa de todas las facultades legales de los Colegios Profesionales para conocer y resolver los conflictos entre profesionales, o entre éstos y sus clientes, y de sancionar las infracciones a la ética profesional, las ahora asociaciones gremiales respectivas continuaron conociendo de dichos asuntos, respaldadas por la jurisprudencia constitucional que llegó a configurar, sobre la base de diversos cuerpos legales, un derecho para juzgar a sus miembros. ${ }^{16}$ Basándose en los artículos 553 y 554 del Código Civil y el artículo 4 del Reglamento sobre Concesión de Personalidad Jurídica a Corporaciones y Fundaciones, nuestros tribunales superiores han establecido las siguientes premisas: 1) los estatutos tienen fuerza obligatoria sobre la entidad; 2) sus miembros están obligados a dichos estatutos bajo las penas que ellos mismos se han impuesto; 3) de lo anterior surge el derecho de la asociación para ejercer la policía correccional; 4) este último debe ejercerse en conformidad a los estatutos; 5) para la efectividad lo anterior, los estatutos deben contemplar las categorías de socios, derechos y obligaciones, condiciones de incorporación y de exclusión, así como los órganos administradores, ejecutivos y controladores, atribuciones y número de miembros. La doctrina rechazaría que la jurisdicción ética o doméstica de estas instituciones se fundara exclusivamente sobre disposiciones legales, aduciendo, en cambio, como fundamento de ella la autonomía de los cuerpos intermedios consagrada en el art. 1 inc. 3 de la Constitución. Según esta postura, lo relevante de que se halle fundada en la Constitución consiste en que la misma Carta contempla un límite a este tipo de jurisdicción, el cual consistiría en que su ejercicio cumpla los fines propios y específicos de la institución, transformándola en una facultad de carácter finalista o teleológica. ${ }^{17}$

${ }^{15}$ Además del artículo citado en la nota precedente, la posición mayoritaria puede apreciarse en Ríos, L., "Los colegios profesionales", en Revista de Derecho Público, Facultad de Derecho, Universidad de Chile, No 59, 1996, pp. 185-205; Silva B., A. y Silva G., M., "Control del comportamiento ético de los profesionales”, en Zúñiga, F. (coord.), Reforma Constitucional, Santiago, LexisNexis, 2005, pp. 305-320. En contra de lo anterior puede consultarse Gandolfo, P., “¿Licencia para informar?”, en Estudios Públicos, Centro de Estudios Públicos, Santiago, N 53, Verano 1994, pp. 263-288; y Andrade, E., "Comentarios sobre la colegiación profesional obligatoria y el estatus jurídico de las asociaciones gremiales profesionales”, en $X X X$ Jornadas Chilenas de Derecho Público, Revista Universidad de Valparaíso, Facultad de Derecho, Universidad de Valparaíso, 1999, tomo I, pp. 109-139.

${ }^{16}$ Art. 3 DL 3.621: "Deróganse todas las disposiciones legales que facultan a los Colegios Profesionales para conocer y resolver los conflictos que se promuevan entre profesionales, o entre éstos y sus clientes, como consecuencia del ejercicio de la profesión, como asimismo aquéllas que les permiten conocer y sancionar las infracciones a la ética profesional". No debe olvidarse que atendido el texto del DL 2.757 , no se contempla expresamente para las asociaciones gremiales una potestad de policía correccional. El artículo $1^{\circ}$ del mismo señala como objeto de las asociaciones gremiales "promover la racionalización, desarrollo y protección de las actividades que les son comunes, en razón de su profesión, oficio o rama de la producción o de los servicios, y de las conexas a dichas actividades comunes".

${ }^{17}$ Fernández, M., "Recurso de protección y jurisdicción doméstica: un principio de solución”, en Revista Chilena de Derecho, Facultad de Derecho, PUC, Vol. 26 N³, 1999, pp. 766-769. 


\section{PosibleS ALCANCES DE LA REFORMA CONSTITUCIONAL}

Teniendo todo lo anterior presente, llegamos finalmente a la Ley 20.050 que agregó el siguiente párrafo al inciso cuarto del artículo 19 número 16:

Los colegios profesionales constituidos en conformidad a la ley y que digan relación con tales profesiones, estarán facultados para conocer de las reclamaciones que se interpongan sobre la conducta ética de sus miembros. Contra sus resoluciones podrá apelarse ante la Corte de Apelaciones respectiva. Los profesionales no asociados serán juzgados por los tribunales especiales establecidos en la ley.

Como se señaló más arriba, esta reforma no fue producto de un intento aislado en nuestra historia reciente, dado que la ética profesional ha sido una preocupación constante en algunos parlamentarios desde el retorno a la democracia, quedando ello demostrado en los diversos proyectos de ley que se presentaron desde inicios de la década de los noventa. Así, se ha intentado establecer la obligación para todas las asociaciones gremiales de contar con un código de ética que regule la conducta de los asociados. ${ }^{18}$ Por otra parte, se pretendió crear un Registro Público de Profesionales dependiente del Registro Civil, consagrando diversas obligaciones como la de encontrarse anotado en dicho registro para poder ejercer la profesión respectiva. ${ }^{19}$ Otra moción tenía por objeto

${ }^{18}$ Boletín N $1969-07$.

${ }^{19}$ Aunque consistía en un solo artículo, dicho proyecto era bastante detallado: En dicho registro serán inscritas todas las personas que ejerzan una profesión para cuyo desempeño era necesario, hasta la vigencia del Decreto Ley 3.621, de 1981, estar inscrito en un Colegio Profesional. Tales inscripciones se practicarán de oficio o a petición del interesado. En el registro se anotará a los profesionales, separados por profesiones, y se dejará constancia de su nombre, apellidos, cédula de identidad, fecha en que obtuvo el título profesional y entidad que se lo otorgó o fecha en que inició el ejercicio de su profesión. Asimismo, se anotarán las sanciones, excepto las de amonestación verbal, que se hayan aplicado por sentencia o resolución ejecutoriada a un profesional, por la ejecución de aquellos actos a que se refieren el artículo $4^{\circ}$ del Decreto Ley 3.621, de 1981. Tales sanciones permanecerán anotadas en el Registro por un plazo de cinco años, contados desde la fecha en que haya quedado ejecutoriada la sentencia o resolución respectiva, transcurrido el cual serán eliminadas de oficio por el Servicio referido, salvo que se trate de la cancelación del título profesional o de la suspensión del ejercicio profesional dispuesta por un plazo superior a dichos cinco años. Será requisito para ejercer una profesión, el estar anotado en el registro que por esta disposición se crea. Las universidades y demás organismos autorizados, que confieran o convaliden títulos profesionales, deberán enviar mensualmente al Servicio de Registro Civil e Identificación, las nóminas de las personas que obtengan un título profesional en el país o que hayan convalidado un título obtenido en el extranjero, para incluirlos en el Registro de Profesionales a cargo de dicho Servicio. Un reglamento del Ministerio de Justicia determinará la forma y demás menciones de dicho registro. El Secretario de la Corte Suprema comunicará mensualmente al Servicio de Registro Civil e Identificación la nómina de personas que hayan recibido el título de abogado en el mes anterior. A la vista de las nóminas que mencionan los incisos precedentes se inscribirá de oficio en el Registro, a los profesionales indicados en ellas. Los Tribunales Ordinarios de Justicia y las asociaciones gremiales a que se refiere el artículo $1^{\circ}$ del presente decreto con fuerza de ley enviarán mensualmente al Ministerio de Justicia, para los efectos previstos en el inciso de este artículo, copia autorizada de las sentencias o resoluciones ejecutoriadas recaídas en los juicios correspondientes. En dichos registros se anotarán, además, las resoluciones que dicten los Tribunales de Ética a que alude el inciso siguiente. Corresponderá 
consagrar como obligación de las universidades el otorgar una formación de graduados y profesionales esencialmente ética. ${ }^{20}$ Específicamente relativo al Colegio de Abogados se procuraría devolverle el control ético relativo al ejercicio de la profesión sobre todos los abogados, y no sólo respecto de aquellos que se encuentran colegiados. ${ }^{21}$ Llama la atención que todos estos proyectos fueron originados por mociones parlamentarias, y los nombres de sus autores se han repetido en algunos de ellos.

Respecto de las posibles consecuencias de la reforma, se puede decir como primera conclusión que, al igual que lo acontecido con la Constitución de 1980 y los Decretos Leyes ya mencionados, no nos encontramos ante una "relación de sujeción especial", por cuanto la relación a la que se somete un profesional que se asocia con un determinado colegio no es una relación pública ni estatal, sino que sigue siendo similar al ingreso que puede hacer cualquier persona en una sociedad, corporación o fundación: esto es, un acto netamente privado, regido por normas de derecho privado, y donde el derecho público tan sólo aparece para el otorgamiento de personalidad jurídica a dichas asociaciones. ${ }^{22}$ Lo que caracterizaba a las demás relaciones de sujeción especial era precisamente ese vínculo acentuado con la Administración del Estado, en el marco de la potestad organizatoria de los órganos estatales, y de obediencia reflexiva a sus superiores jerárquicos. Si tuviesen el carácter de entes paraestatales, a los cuales todos los profesionales estuvieran obliga-

a la organización gremial más representativa de cada profesión velar por la conducta ética de las personas que figuren en el Registro de Profesionales, a través de un Tribunal Nacional de Ética Profesional o, en su caso, de Tribunales Regionales de Ética Profesional, de conformidad con esta ley. Los referidos tribunales estarán integrados por profesionales afiliados a la entidad gremial a que alude el inciso precedente y serán designados conforme a los estatutos de la misma. Estos tribunales, de oficio o a petición de parte interesada, informará a la Directiva de la Orden y, en su caso, a los Tribunales de Justicia, acerca de si la conducta de un profesional ha sido acorde o no con los valores morales que rigen la correspondiente actividad profesional. Este informe, para efectos judiciales, equivaldrá a un informe de peritos. Sin perjuicio de lo anterior el Tribunal Nacional o los Tribunales Regionales podrán adoptar las sanciones de amonestación o censura, cuando estime que un profesional ha obrado contrariando las referidas normas éticas. De las resoluciones de los Tribunales Regionales de Ética Profesional podrá apelarse para ante el Tribunal Nacional de Ética Profesional respectivo. El procedimiento que se seguirá ante estos tribunales se establecerá en los estatutos de las entidades gremiales, con pleno respeto a las normas del debido proceso. Créase en cada Hospital Base, sea público o privado, un Comité de Ética Médica, el que prestará su colaboración y asesoría al respectivo Director del Establecimiento, en el conocimiento y resolución de los problemas que plantea la práctica de la medicina, con el objeto de promover y fiscalizar la observancia de los valores ético-profesionales que la rigen. Será obligación tanto de los directores de los establecimientos como de los facultativos y demás personas que allí laboran prestar la cumplida colaboración que soliciten dichos comités. Un reglamento del Ministerio de Salud determinará la composición y funcionamiento de estos comités. Será obligación de los Tribunales de Justicia que conozcan de causas civiles o criminales originadas en la práctica dolosa, negligente o defectuosa de una profesión requerir un informe ético al Tribunal Regional de Ética Profesional, y, a falta de éste, al Tribunal Nacional”. Boletín No 1770-07.

${ }^{20}$ Boletín $\mathrm{N}^{\mathrm{o}} 1755-04$.

${ }^{21}$ Boletín $\mathrm{N}^{\circ} 1494-07$.

${ }^{22}$ El artículo $2^{\circ}$ del Decreto Ley 2.757 señala que la afiliación a una de estas asociaciones es un acto voluntario, y no puede obligarse a nadie a hacerlo para desarrollar una actividad ni tampoco impedírsele su afiliación. Le corresponde al Ministerio de Economía, Fomento y Reconstrucción llevar el registro de estas asociaciones $\left(\operatorname{art} .4^{\circ}\right)$. 
dos a afiliarse, estaríamos en mejor pie para aceptar dicha posibilidad. La exigencia de colegiarse obligatoriamente implica una restricción previa al ejercicio de una profesión y de los derechos fundamentales que a ella son connaturales, restricción que para ser admitida debería tener asidero en el texto constitucional, lo cual no es el caso. ${ }^{23}$

En todo caso, la anomalía antes descrita persiste en forma disminuida ya que la Constitución le reconoce a los colegios competencia exclusiva para conocer de las reclamaciones que se interpongan sobre la conducta ética de sus miembros, y la asimila al ejercicio de la potestad jurisdiccional; conclusión a la que se llega si se atiende que serán los tribunales ordinarios, y posteriormente si se crean, tribunales especiales, quienes conozcan aquellas infracciones a la conducta ética de los profesionales no asociados. ${ }^{24}$ En términos procesales, el alcance de la reforma consiste en que ante las conductas realizadas por un colegiado que pudieran contravenir la ética profesional, el afectado se encontraría obligado a reclamar al respectivo colegio sin poder acudir a los tribunales de justicia. ${ }^{25}$

Por último, desde el punto de vista de la denominada jurisdicción doméstica, la reforma devolvería la facultad de conocer de las reclamaciones que se interpongan sobre la conducta ética de sus miembros, produciéndose una antinomia de primer grado entre el artículo $3^{\circ}$ del DL 3.621 y el art. 19 N 16 de la Constitución, la cual se resolvería a favor de esta última norma conforme a los criterios de jerarquía y temporalidad. Con ello, se institucionalizaría la situación que por veintiséis años mantuvo a los Colegios Profesionales actuando de manera legalmente discutible, aun cuando se fundara sobre la base de argumentos jurisprudenciales y doctrinarios. Pero ello de ningún modo no implica ampliar el rango de competencia de los colegios, por cuanto los términos del texto constitucional resultan similares a lo que el Código Civil denomina derecho de policía correccional, que más que un derecho, es una potestad de ordenación de carácter privado. ${ }^{26}$ Por lo que en lo relativo a su alcance o naturaleza, se asimilaría bastante a ella.

${ }^{23}$ Así lo entendió el juez Rodolfo Piza, de la Corte Interamericana de Derechos Humanos, en su voto concurrente en el caso Tico/Times: "Yo considero que la colegiación obligatoria de los periodistas constituye una restricción de esa naturaleza, cuyo específico sentido normativo es el de prevenir el ejercicio mismo de la actividad periodística, coincidente, como ya se dijo, con el de la libertad de expresión, sometiéndolo a la condición de una licencia o autorización, y, por ende, el de condicionar la propia libertad a una restricción stricto sensu no autorizada como tal por el artículo 13.2 de la Convención. De esta manera, creo que la colegiación obligatoria de los periodistas es, en sí misma, incompatible con la Convención, cualquiera que sea el modo como se reglamente y aunque sólo constituyera una formalidad asequible a cualquier persona que quisiera ejercer el periodismo, sin necesidad de ningún requisito adicional. La libertad de expresión es un derecho fundamental de todo ser humano por el solo hecho de serlo, cuyo ejercicio no puede ser restringido ni condicionado al cumplimiento de requisitos previos de ninguna naturaleza que él no pueda o no quiera cumplir”. Disponible en Estudios Públicos, Santiago, No 53, Verano 1994, p. 371.

${ }^{24}$ Ver artículo 20 transitorio de la Constitución.

${ }^{25}$ Así lo ha destacado Silva, B. y Silva, G., "Control del comportamiento...", cit., p. 318.

${ }^{26}$ Art. 554: "Toda corporación tiene sobre sus miembros el derecho de policía correccional que sus estatutos le confieran, y ejercerán este derecho en conformidad”. Así lo señaló el presidente del Colegio de 


\section{¿TRIUNFO GREMIAL O REGALO TROYANO?}

Ahora bien, ¿favorece o no la reforma constitucional a los colegios profesionales? A primera vista se podría pensar que la reforma respondió a las demandas gremiales y reivindicó el rol de los colegios profesionales en lo relativo al control ético del actuar profesional. Aún más, con el reconocimiento de esta jurisdicción ética, surge la posibilidad de que estas asociaciones gremiales lleguen a configurar el derecho vigente; en otras palabras, "se ha desplazado el rol concretizador de la Carta, usualmente reconocido a los órganos del Estado, a cuerpos intermedios". ${ }^{27}$ Existen ejemplos legislativos de la afirmación anterior, como sucede en el caso de la denominada Ley de Culto, que en su artículo $9^{\circ}$ reconoce como fuente para adquirir la personalidad jurídica a las normas jurídicas propias de cada iglesia. ${ }^{28}$ Otra muestra se encuentra en el art. $54^{\circ}$ de la Ley Indígena que reconoce a la costumbre indígena no sólo como fuente de derecho, en la medida que sea compatible con la Constitución, sino que incluso como eximente o atenuante de responsabilidad penal. ${ }^{29}$ El caso concreto de esta posible configuración del derecho por parte de los colegios lo encontramos en el alcance que podrían tener los respectivos códigos deontológicos en aquellos conflictos en que sean los tribunales de justicia quienes conozcan de reclamaciones sobre actuaciones de profesionales no colegiados que puedan infringir la ética profesional.

Una primera solución a este problema la establecía el Decreto Ley 3.621 en su artículo $2^{\circ}$ transitorio, el cual señalaba que los códigos se entendían vigentes mientras el Presidente de la República no dictara nuevas reglas al respecto en un plazo de 6 meses,

Arquitectos A.G. a la comisión del Senado. Pfeffer, E., Reformas Constitucionales 2005. Antecedentes-DebatesInformes, Santiago, Editorial Jurídica de Chile, 2005, p. 92.

${ }^{27}$ Aldunate, E., “Asociaciones intermedias, Constitución, Estado y Bien Común”, en XXX Jornadas Chilenas de Derecho Público, Revista Universidad de Valparaíso, Facultad de Derecho, Universidad de Valparaíso, 1999, tomo I, p.104. Estaríamos ante un tipo de subderecho, producido en la subcultura de grupos profesionales, creando un derecho degradado o por lo menos imperfecto por no tener origen estatal. Carbonnier, J., Derecho Flexible. Para una sociología no rigurosa del Derecho, Madrid, Tecnos, 1974, p. 34.

${ }^{28}$ Artículo $9^{\circ}$ : "Las asociaciones, corporaciones, fundaciones y otros organismos creados por una iglesia, confesión o institución religiosa, que conforme a sus normas jurídicas propias gocen de personalidad jurídica religiosa, son reconocidos como tales. Acreditará su existencia la autoridad religiosa que los haya erigido o instituido. Las entidades religiosas, así como las personas jurídicas que ellas constituyan en conformidad a esta ley, no podrán tener fines de lucro”. Ley 19.638, publicada 14/10/1999.

${ }^{29}$ Artículo 54: "La costumbre hecha valer en juicio entre indígenas pertenecientes a una misma etnia, constituirá derecho, siempre que no sea incompatible con la Constitución Política de la República. En lo penal se la considerará cuando ello pudiere servir como antecedente para la aplicación de una eximente o atenuante de responsabilidad. Cuando la costumbre deba ser acreditada en juicio podrá probarse por todos los medios que franquea la ley y, especialmente, por un informe pericial que deberá evacuar la Corporación a requerimiento del Tribunal. El Juez encargado del conocimiento de una causa indígena, a solicitud de parte interesada y en actuaciones o diligencias en que se requiera la presencia personal del indígena, deberá aceptar el uso de la lengua materna debiendo al efecto hacerse asesorar por traductor idóneo, el que será proporcionado por la Corporación”. Ley 19.253, publicada 5/10/1993. 
lo cual nunca sucedió. ${ }^{30}$ Por otra parte, ha existido alguna jurisprudencia que se ha pronunciado al respecto. En Berstein K., Ricardo con Albónico V., Fernando, la Corte de Apelaciones de Santiago señaló, en su considerando $4^{\circ}$, que al no haber hecho uso el Presidente de las facultades mencionadas dentro de dicho plazo, "deben entenderse aplicables a los conflictos que se susciten las sanciones y las normas de ética contenidas en las leyes orgánicas de los respectivos colegios profesionales, vigentes a la fecha del Decreto Ley 3.621, de 1981"31. Una primera lectura podría hacer creer que la situación entre un profesional colegiado y uno no colegiado no variaría, entonces, en cuanto a las normas que deben regir su actuar profesional. Pero existen fuertes argumentos para no poder aceptar dicha extensión.

Primero, por pertenecer a la tradición jurídica europeo-continental, en Chile las decisiones judiciales tienen un efecto relativo: ellas obligan sólo a los litigantes correspondientes, no a otros jueces ni al mismo juez que juzgue otros casos. Por ende, la ausencia de stare decisis permite la posibilidad de que en cualquier momento los jueces decidan de otra manera. Segundo, el abogado involucrado en el caso mencionado era miembro voluntario del Colegio de Abogados, por lo que el código formaba parte de la normativa propia de su afiliación. Resumiendo, desde un punto de vista normativo, el alcance del código es dudoso, especialmente en relación con aquellos abogados que no son miembros del Colegio. ${ }^{32}$

En cambio, y dado que persiste el problema relativo a la posibilidad o no de extensión de los códigos deontológicos como derecho aplicable por parte de la judicatura, una segunda mirada a la reforma en cuestión se mostraría menos optimistas por cuanto dichas asociaciones gremiales podrían ver disminuidas sus potestades sobre sus miembros y, en especial, cuestionados sus códigos y órdenes internas, ya que respecto a todas sus decisiones en procedimientos sobre conductas atentatorias de la ética, la propia Constitución contempla que ellas sean susceptibles de ser apeladas ante la Corte de Apelaciones respectiva. Esto resulta paradójico, por cuanto con anterioridad al DL 3.621 no se otorgaba competencia en segunda instancia en términos tan amplios, sino que tan sólo en forma excepcional y acotada. En el caso del Colegio de Abogados, el DL 406

${ }^{30}$ Artículo $2^{\circ}$ : "Facúltase al Presidente de la República para dictar, en el plazo de 6 meses, los decretos con fuerza de ley que estime necesarios, para entregar a otras entidades las atribuciones o funciones que tuvieren los Colegios en la actualidad y que no sean compatibles con el carácter de las Asociaciones regidas por el decreto ley 2.757, o que no fueren asumidas adecuadamente por ellas. Podrá asimismo el Presidente de la República, a través de decretos con fuerza de ley y dentro de igual plazo, dictar o modificar las normas que reglamenten el ejercicio de las profesiones correspondientes o la ética profesional”.

${ }^{31}$ En RDJ, tomo LXXXV (1988), No 1 (enero-abril), sección 2.

${ }^{32}$ Sierra, Legal Ethics in Chile..., cit., p. 59. En todo caso, los códigos deontológicos desde la entrada en vigencia del Código Civil han tenido relevancia jurídica en la interpretación judicial de las palabras técnicas de toda ciencia o arte, en los términos del art. 21. También pueden ser relevantes en casos de responsabilidad extracontractual para determinar el estándar de cuidado, por cuanto los códigos aspiran a ser la ley propia de cada arte (lex artis ad hoc). 
contemplaba la intervención de la Corte Suprema sólo para el caso en que la sanción acordada por el Consejo respectivo fuese la cancelación del título profesional, para lo cual requería la aprobación de la Corte. ${ }^{33}$ Posteriormente la Ley 4.409 permitió apelar ante el mismo tribunal en el caso de que se sancionará al abogado con la cancelación del título. Y para el conocimiento de las implicancias y recusaciones de los miembros del Consejo respectivo, contemplaba la creación de un tribunal interno integrado por miembros del propio Consejo, si no se podía constituir dicho tribunal, debía conocer la Corte de Apelaciones respectiva para el solo efecto de determinar la procedencia de las causales invocadas. ${ }^{34}$ Lo mismo puede señalarse en los casos del Colegio Médico, de Dentistas y de Enfermeras, en los cuales además de lo referido a la cancelación del título, la ley contemplaba una segunda instancia interna ante el Consejo General del respectivo Colegio, en los casos en que se sancionara al profesional respectivo con censura o con la suspensión del ejercicio de la profesión por un plazo no superior a seis meses. ${ }^{35}$ Por otra parte, aun cuando el artículo $4^{\circ}$ del Decreto Ley 3.621 señala que los conflictos que versen sobre actos desdorosos, abusivos o contrarios a la ética se consideran de carácter contencioso civil y su tramitación se sujeta a las reglas del juicio sumario, en la actualidad ello resultaría sólo aplicable para los profesionales no afiliados.

A esto cabe agregar que el control judicial sobre los procedimientos disciplinarios de estas entidades ya había comenzado con anterioridad a la reforma, si se atiende a la jurisprudencia que ha extendido las garantías de un racional y justo procedimiento y de otros derechos fundamentales a dichos procesos. ${ }^{36}$ Lo recién señalado no constituye la regla general en la jurisprudencia recaída sobre acciones de protección en materia de jurisdicción doméstica, existiendo fallos en los cuales se ha negado lugar a los recursos por considerar que no se han afectado derechos constitucionales o por estimar que carecen de competencia para revisar las resoluciones adoptadas por las asociaciones gremiales. Pero también se han acogido algunos cuando, analizada la situación de hecho, las Cortes han considerado acreditada una actuación lesiva de la Constitución. ${ }^{37}$

Esta última situación ha sido criticada por alguna doctrina, en especial por la extensión no sólo del debido proceso legal sino también de la prohibición general de juzgamiento por comisiones especiales. En general, dicha extensión a todo tipo de ámbitos ha sido posible por la interpretación exegética del numeral 3 cuando utiliza la expresión 'órgano

${ }^{33}$ Artículo 10 DL 406. Por otra parte, para el caso de aquellas personas que se consideraban víctimas de la forma de actuar de algún abogado, ellas podían reclamar ante el Consejo, pero si llegaban a hacer públicas tanto el reclamo como la decisión sin acuerdo expreso del Consejo, serían multadas según lo dictaminara el Juez de Letras en lo Civil, dentro de un rango de \$500 a \$1.000 pesos. Art. 11 DL 406.

${ }^{34}$ Artículos 18 y 20 Ley 4.409.

${ }^{35}$ Artículos 9 letra d), 29 y 31 de las Leyes 9.263 y 9.271 y artículos 10 letra d), 24 y 26 de la Ley 11.161 .

${ }^{36}$ Por ejemplo, Asahi Senda, Tadashi con Directorio Nacional del Colegio de Arquitectos de Chile, e Hidalgo Rojas, Álvaro y otros con Consejo General del Colegio Médico de Chile A.G., en RDJ, tomo LXXXV (1988), N N $^{\circ}$ (enero-abril), sección 5.

${ }^{37}$ Fernández, M., "Recurso de protección...”, cit., pp. 761-762, quien considera errática esta práctica jurisprudencial. 
que ejerza jurisdicción', en su inciso $5^{\circ}$. Con ello, "lo jurisdiccional se amplía hacia ámbitos extensísimos, excediendo los parámetros ordinarios que se reconocen con esta función en la doctrina". ${ }^{38}$ Estos argumentos, planteados respecto a la constitucionalización del poder público en aquellos casos en que la Administración resuelve asuntos sometidos a su decisión, podrían aplicarse a la situación de los colegios profesionales. Esta extensión de las garantías constitucionales a procedimientos disciplinarios de asociaciones privadas ha sido criticada por Correa, quien señala al comentar jurisprudencia reciente, que este tipo de organizaciones requieren por su naturaleza facultades disciplinarias y que en el ejercicio de ellas "pueden privar a los asociados de los derechos que les da la asociación, llegando incluso a su expulsión. Estos procedimientos no se rigen por los estándares constitucionales. No corresponde a la Corte Suprema convertirse en panel de revisión de medidas disciplinarias de asociaciones". 39

La reforma viene a acentuar esta situación, permitiendo un nuevo control, ahora incluso directo, sobre sus decisiones al consagrar constitucionalmente el recurso de apelación, lo que sumado a la jurisprudencia de protección y a la posibilidad de recurrir ante el Tribunal Constitucional para declarar inaplicable una disposición de los códigos respectivos, pone en duda los beneficios que recuperar el control disciplinario traería para las respectivas asociaciones, al menos en los términos actualmente establecidos. Por otra parte, el mandato constitucional dirigido al legislador se refiere a la situación de los profesionales no colegiados, en cuanto a la creación de tribunales especiales en la materia, y no respecto a los colegiados, lo que debería producir una verdadera tensión respecto al establecimiento de órganos jurisdiccionales estatales, independientes, imparciales, que se rigen por normas legales, y que someten su actuar a un procedimiento racional y justo, frente a otros que se encuentran sometidos a una jurisdicción de carácter más bien convencional.

\section{A MODO DE CONCLUSIÓN}

Después de lo señalado con anterioridad, la siguiente pregunta refleja el fondo del asunto: ¿el control jurisdiccional sobre los colegios implica el camino a la aniquilación de su autonomía?

${ }^{38}$ Agrega lo siguiente: "Aún más, si se lee con detención el art. $8^{\circ}$ del Pacto de San José de Costa Rica, vemos que la exigencia del debido proceso legal se plantea respecto de un procedimiento judicial -'toda persona tiene derecho a ser oída, con las debidas garantías y dentro de un plazo razonable, por un juez o tribunal competente, independiente e imparcial...' -, lo que confirma la interpretación restrictiva que se ha planteado". Ferrada, J. C., "La progresiva constitucionalización del poder público administrativo chileno: un análisis jurisprudencial”, en Ferrada (coord.), La constitucionalización del derecho chileno, Santiago, Editorial Jurídica de Chile, 2003, pp. 78-79.

${ }^{39}$ Correa, R., "Derechos Constitucionales", en Revista de Derecho de la Universidad Adolfo Ibáñez, No I, 2004, p. 573. 
La pregunta anterior, como posibilidad de control judicial, así como la anteprecedente, respecto de las posibilidades que se le reconozcan al Estado para calificar la juridicidad de las normas internas del grupo, llevan a plantearse la pregunta de si el reconocimiento de los cuerpos intermedios y su autonomía es compatible con la 'juridización de los mismos'. Y esto porque, en la medida en que se juridizan y se someten a los controles estatales, se abandona el concepto de entes sociales en oposición al Estado, y se pasa a uno en los cuales el Estado pasa a intervenir. Por una parte se les reconoce generosamente autonomía hasta el punto de las propias normas; pero este regalo troyano lleva en sí la necesidad y posibilidad de control, y por esta vía, de intervención. ${ }^{40}$

La reforma, al asimilar la potestad de los colegios profesionales a la de los tribunales, permite justificar esta extensión de los derechos fundamentales a los procesos internos que la jurisprudencia ha realizado durante los últimos años, olvidando las advertencias de parte de la doctrina. Y, sumado a esto, la consagración constitucional de la doble instancia abre a posibilidad de revisar sus propios estándares éticos a la luz de las Cortes de Apelaciones, restándoles parte de su autonomía propia como cuerpos intermedios. Ello lleva a preguntarse si los colegios profesionales han ganado realmente algo con esta última reforma y si, consecuentemente con ella, existirá un verdadero debate sobre la ética en el ámbito profesional más allá de las paredes de dichas asociaciones, o tan solo habrán recibido un regalo troyano. ${ }^{41}$

\section{BIBLIOGRAFÍA}

Aldunate, E., “Asociaciones intermedias, Constitución, Estado y Bien Común”, en XXX Jornadas Chilenas de Derecho Público, Revista Universidad de Valparaíso, Facultad de Derecho, Universidad de Valparaíso, 1999, tomo I, pp. 101-107.

- "La titularidad de los derechos fundamentales", en Estudios Constitucionales, N N 1, 2003, pp. 187-201.

Andrade, E., "Comentarios sobre la colegiación profesional obligatoria y el estatus jurídico de las asociaciones gremiales profesionales", en XXX Jornadas Chilenas de Derecho Público, Revista Universidad de Valparaíso, Facultad de Derecho, Universidad de Valparaíso, 1999, tomo I, pp. 109-139.

Carbonnier, J., Derecho Flexible. Para una sociología no rigurosa del Derecho, Madrid, Tecnos, 1974.

\footnotetext{
${ }^{40}$ Aldunate, “Asociaciones intermedias...”, cit., p. 105.

${ }^{41}$ En el plano legislativo, la reforma ha comenzado a hacer ruido, como puede verse en el proyecto de ley en trámite, que rememora algunas disposiciones previas al DL 3.621, el cual busca responsabilizar al presidente de un organismo colegiado respecto a la convocatoria a sesiones ordinarias o extraordinarias. moción de los parlamentarios Maximiano Errázuriz, Amelia Herrera y Marta Isasi, ingresada 08/03/07 (Boletín 4890-07).
} 
Carmona, C., "Comentario N ${ }^{\circ} 1$. Fallo Norgener", en Revista de Derecho Público, Facultad de Derecho, Universidad de Chile, Volumen 62, 2000, pp. 308-321.

Cordero, L., "Los particulares como sujetos de derecho en el Derecho Administrativo. Bases para una sistematización”, en Revista de Derecho Público, Facultad de Derecho, Universidad de Chile, Vol. 64, 2002, pp. 213-236.

Correa, R., "En defensa de una aplicación exclusivamente vertical de los derechos constitucionales", en VI Congreso Mundial de Derecho Constitucional, 13 de enero de 2004, Santiago, Chile.

- "Derechos Constitucionales", en Revista de Derecho de la Universidad Adolfo Ibáñez, N I, 2004, pp. 563-587.

FERnÁndez, M., "Recurso de protección y jurisdicción doméstica: un principio de solución”, en Revista Chilena de Derecho, Facultad de Derecho, PUC, Vol. 26 N³, 1999, pp. 761-781.

FERnÁndez, T-R., "Del servicio público a la liberalización desde 1950 hasta hoy", en Revista de Administración Pública, $\mathrm{N}^{\circ} 150,1999$, pp. 57-73.

Ferrada, J. C., "La progresiva constitucionalización del poder público administrativo chileno: un análisis jurisprudencial”, en Ferrada (coord.), La constitucionalización del derecho chileno, Santiago, Editorial Jurídica de Chile, 2003, pp. 63-98.

Gallego, A., "Las relaciones especiales de sujeción y el principio de la legalidad de la Administración”, en Revista de Administración Publica, No 34, 1961, pp. 11-51.

Gandolfo, P., “¿Licencia para informar?”, en Estudios Públicos, Centro de Estudios Públicos, Santiago, N N $^{\circ} 3$, Verano 1994, pp. 263-288.

García M., R., Las relaciones de especial sujeción en la Constitución española, Madrid, Editorial Tecnos, 1992.

Góngora, M., Ensayo histórico sobre la noción de Estado en Chile en los siglos XIX y XX, Santiago, Editorial Universitaria, 1998.

Gyarmati, G., Las profesiones. Dilemas del conocimiento y del poder, Santiago, Ediciones Universidad Católica de Chile, 1984.

Lasagabaster, I., Las relaciones de sujeción especial, Madrid, Civitas, 1994.

Mayer, O., Derecho Administrativo alemán, Buenos Aires, Depalma, 2a. ed., Vol. 1, 1982.

Pfeffer, E., Reformas Constitucionales 2005. Antecedentes-Debates-Informes, Santiago, Editorial Jurídica de Chile, 2005.

Ríos, L., "Los colegios profesionales", en Revista de Derecho Público, Facultad de Derecho, Universidad de Chile, $\mathrm{N}^{\circ}$ 59, 1996, pp. 185-205.

- "Las asociaciones, el derecho de asociación y los colegios profesionales", en XXX Jornadas Chilenas de Derecho Público, Revista Universidad de Valparaíso, Facultad de Derecho, Universidad de Valparaíso, 1999, tomo I, pp. 141-158.

Sierra, L., Legal Ethics in Chile: Professional Dilemmas and Challenges under Conditions of Modernization, inédito, 1995.

- "Derecho, cambio social y los juristas en Chile: de la estridencia de los 60 al silencio de hoy", en AA.VV., El derecho como objeto de instrumento de transformación, Buenos Aires, Editores del Puerto, 2003, pp. 31-46.

Silva B., A. y Silva G., M., "Control del comportamiento ético de los profesionales”, en Zúñiga, F. (coord.), Reforma Constitucional, Santiago, LexisNexis, 2005, pp. 305-320.

Silva C., E., Derecho Administrativo chileno y comparado, Santiago, Editorial Jurídica de Chile, tomo II, 1961. 